\title{
Low-cost acoustic design of a bat test room
}

\section{R. Correia, C. Faneca, D. Albuquerque, J. Vieira, C. Bastos, C. Fonseca \& M.J. Ramos Pereira}

To cite this article: R. Correia, C. Faneca, D. Albuquerque, J. Vieira, C. Bastos, C. Fonseca \& M.J. Ramos Pereira (2015) Low-cost acoustic design of a bat test room, Bioacoustics, 24:1, 81-87, DOI: $10.1080 / 09524622.2014 .964772$

To link to this article: http://dx.doi.org/10.1080/09524622.2014.964772

\section{曲 Published online: 07 Oct 2014.}

\section{Submit your article to this journal $\widetilde{ }$}

山 Article views: 90

Q View related articles $₫$

View Crossmark data $₫$ 


\title{
Low-cost acoustic design of a bat test room
}

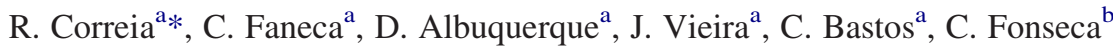 \\ and M.J. Ramos Pereira ${ }^{b}$ \\ ${ }^{a}$ Department of Electronics Telecommunications and Informatics, University of Aveiro, 3810-193 \\ Aveiro, Portugal; ${ }^{b}$ Department of Biology, Centre for Environmental and Marine Studies (CESAM), \\ University of Aveiro, 3810-193 Aveiro, Portugal
}

(Received 28 May 2014; accepted 5 September 2014)

\begin{abstract}
Experiments with captive bats need a flight room that is acoustically neutral, especially when recording and analysing bat calls or the response of bats to certain sound stimuli. Our aim was to identify an isolation material with the best quality-price relationship to acoustically coat such a flight room. For this, we built a flight room divided into two compartments that were to be acoustically isolated from one another. Audible and infrasonic waves are difficult to attenuate with low-cost materials but the attenuation of ultrasounds is rather straightforward. We evaluated the absorbing capacities of different low-cost materials - felt fabric, polystyrene, egg boxes, egg boxes coated with felt fabric, absorbing pyramidal foams, polyurethane foams and cork. The material that showed the best quality-price relationship was the polyurethane foam of open cells ( $5 \mathrm{~cm}$ thickness), which was able to attenuate approximately $20 \mathrm{~dB}$ at ultrasonic frequencies.
\end{abstract}

Keywords: acoustic isolation; acoustic simulator; bat test room; captivity experiments; Chiroptera; neutral flight room

\section{Introduction}

The sound heard in most environments is a combination of direct sound coming straight from a source and its indirect reflections from surfaces (Cox and D'Antonio 2009). The same happens when a microphone picks up a sound in a closed environment or room. In a free field or anechoic chamber, there is only direct sound and no reflection exists, but most environments are not like this. In fact, indirect sound, immediately following direct sound, results from all the various non-free-field effects characteristic of an enclosed space. Everything that is not direct sound is indirect sound (reflected or dispersed). The type and intensity of indirect sounds are associated with the acoustical response of the room, and are closely dependent on the construction materials, such as those of doors, windows, walls, floors and ceiling. These materials are set into vibration by the source sound, and decay at their own particular rate when excitation is removed (Everest and Pohlmann 2009).

An untreated workspace is merely a container of air particles responsible for the propagation of sound and practically all attenuation of sound - emitted signals as well as noise - takes place at the boundaries of this airspace. Indeed, the absorption of sound by the air itself is negligible in small rooms. Carpet on the floor, lay-in panels on the ceiling and absorbent materials on the wall surfaces will reduce the energy of reflected sounds (Everest and Pohlmann 2009).

*Corresponding author. Email: rjoao@ua.pt 
The choice of the absorbing material with which to coat an acoustically neutral room is determined by the distribution of the noise (reflection) frequencies to be absorbed and the acoustic absorption profile required. In many cases, it is also determined by the cost of the available materials.

As part of a larger research and development project, we aimed to study bat behaviour in captivity. As these animals emit ultrasounds to navigate and forage (Griffin et al., 1958), we needed to build an acoustically neutral test room, where echoes were as reduced as possible. In this context, our objective was to identify an isolation material with the best quality-price relationship to acoustically coat a bat flight room. For this, we analysed and compared the absorbing capacities of different low-cost materials.

\section{Materials and methods}

Manufacturers of sound insulation materials usually do not evaluate or publish acoustic measurements for frequencies above $20 \mathrm{kHz}$. In fact, because these are frequencies beyond the hearing ability of the human ear, manufacturers may not even have the necessary equipment for measuring the ultrasonic range.

We implemented an acoustic simulator in Matlab and tested the isolation behaviour of several materials. The room acoustics simulator is based on a hybrid method that considers all wave reflections as specular, which is a good approximation to the way the sound waves propagate in a closed space whenever the wavelength is much smaller than the obstacles. For more details, see Albuquerque et al. (2009). The simulator takes into account the attenuation due to air propagation losses (as a function of the signal frequency, air temperature, pressure and humidity), potential wall reflections and the characteristics of the source and receiver beams.

\section{Measurements of the absorption characteristics of the materials}

We used a piezo-tweeter speaker Kemo L010 (Kemo Electronic GmbH, Langen, Germany), a power amplifier TDA7850 12VDC (ST Microelectronics, Geneva, Switzerland), a microphone B\&K 4954A (Bruel \& Kjaer, Naerum, Denmark), a sound card Octa-Capture 10-10 (Roland, Los Angeles, USA) and a personal computer to collect the data. The frequency response of the microphone can be seen in Figure 1(a) and the frequency response of the speaker in Figure 1(b). The microphone was connected to the sound card input, the amplifier of the tweeter was connected to the sound card output and the sound card was also connected to the computer via USB to register the data. The microphone and the speaker were placed side by side at a distance of $5.5 \mathrm{~cm}$; both microphone and speaker were set in front of a $151.0 \mathrm{~cm} \times 121.0 \mathrm{~cm} \times 1.4 \mathrm{~cm}$ wood board at a distance of $89.0 \mathrm{~cm}$, and a distance of $130.0 \mathrm{~cm}$ from the ground and $170.0 \mathrm{~cm}$ from the ceiling (Figure 2(a)).

The speaker was programmed to emit chirps of frequencies between 0 and $96 \mathrm{kHz}$ with a duration of $5 \mathrm{~s}$ to get a good signal-to-noise ratio. The microphone sampled the received signal at $192 \mathrm{kHz}$. As expected, the microphone captured two distinct energy peaks - one corresponding to the direct propagation of the sound and the other resulting from sound reflection (Figure 2(b)). Because we were aiming to identify the best isolation material, we only analysed the second peak. By performing the cross-correlation of this second peak with the transmitted chirp, we obtain an estimation of the impulse response of the tested material (Farina, 2000). Evaluating the Discrete Fourier Transform of this impulse response, we get the frequency components of the reflected signal (Figure 4). 


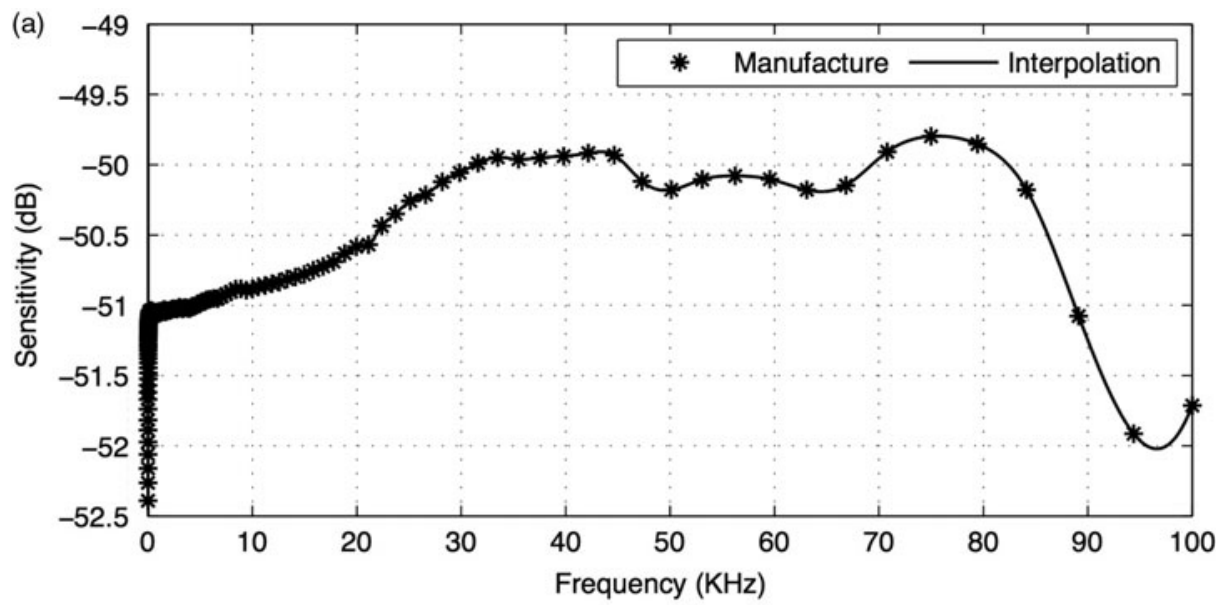

(b)

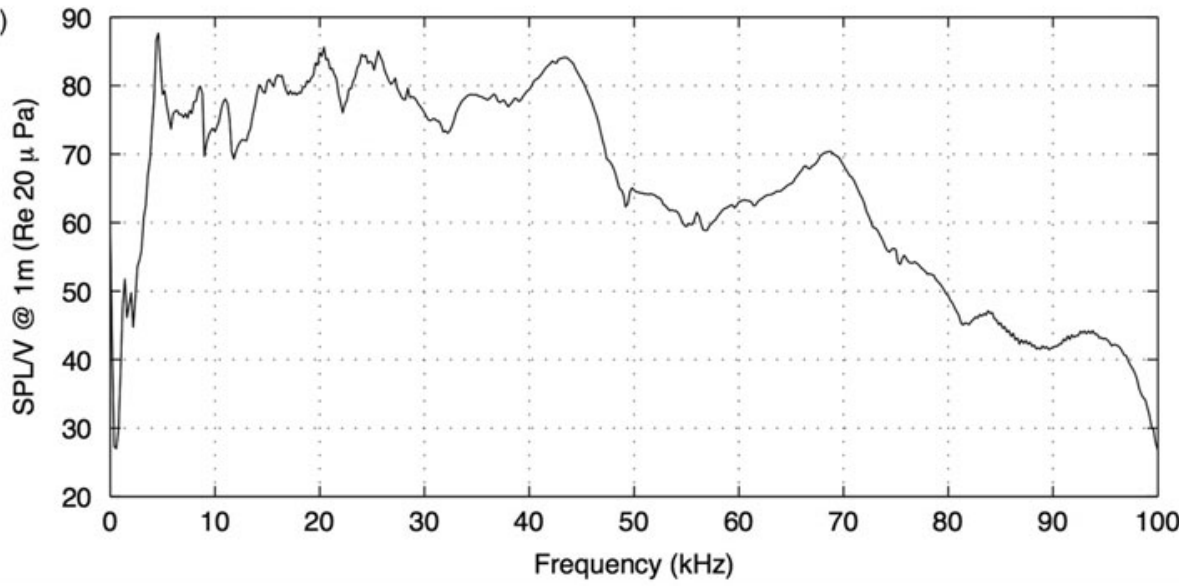

Figure 1. (a) Frequency response of microphone Bruel and Kjaer (4954A). (b) Frequency response of speaker Kemo L010.

We analysed the sound-absorbing capacities of nine distinct materials - felt fabric, polystyrene, egg boxes, egg boxes coated with felt fabric, absorbing pyramidal foams, polyurethane foams with different thicknesses $(1,3$ and $5 \mathrm{~cm})$ and cork ( $3 \mathrm{~mm}$ thickness) (Figure 3) - with which we covered the board, and compared their acoustic responses with those of the non-coated board. These materials were selected because they are known to be used for acoustic isolation and are relatively cheap materials (in fact their price per square metre ranges from $7 €$ to $25 €$ while the material usually sold by manufacturers for sound isolation costs about $40 €$ ). We also coated the wall below the board with foam to reduce potential sound reflections. The description of the materials used can be seen in Table 1 .

All experiments were carried out under similar conditions: temperature of $21^{\circ} \mathrm{C}$, atmospheric pressure of $1 \mathrm{~atm}$ and relative humidity of $40 \%$.

\section{Results}

The material that presented the best absorption behaviour was the 5-cm thickness polyurethane foam (Figure 4). It presented better results than any of the remaining tested 

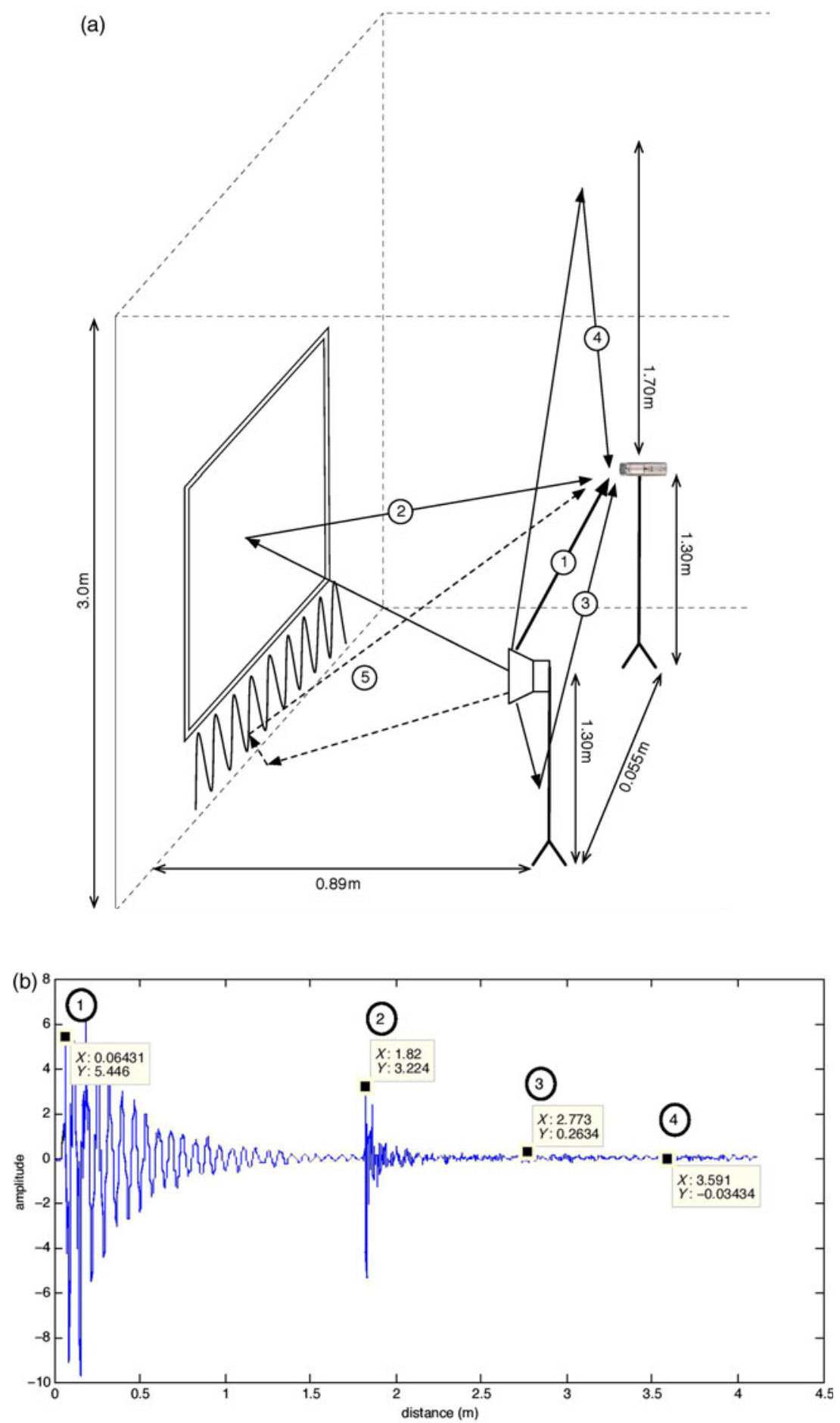

Figure 2. (a) Distances in the room; 1, direct propagation; 2, reflection from the board; 3, reflection from the ground; 4, reflection from the ceiling; 5, reflection from the ground and wall, absorbed by the foam. (b) Signal captured by microphone from direct propagation (1) and from the reflection of the board (2), the ground (3) and ceiling (4). 

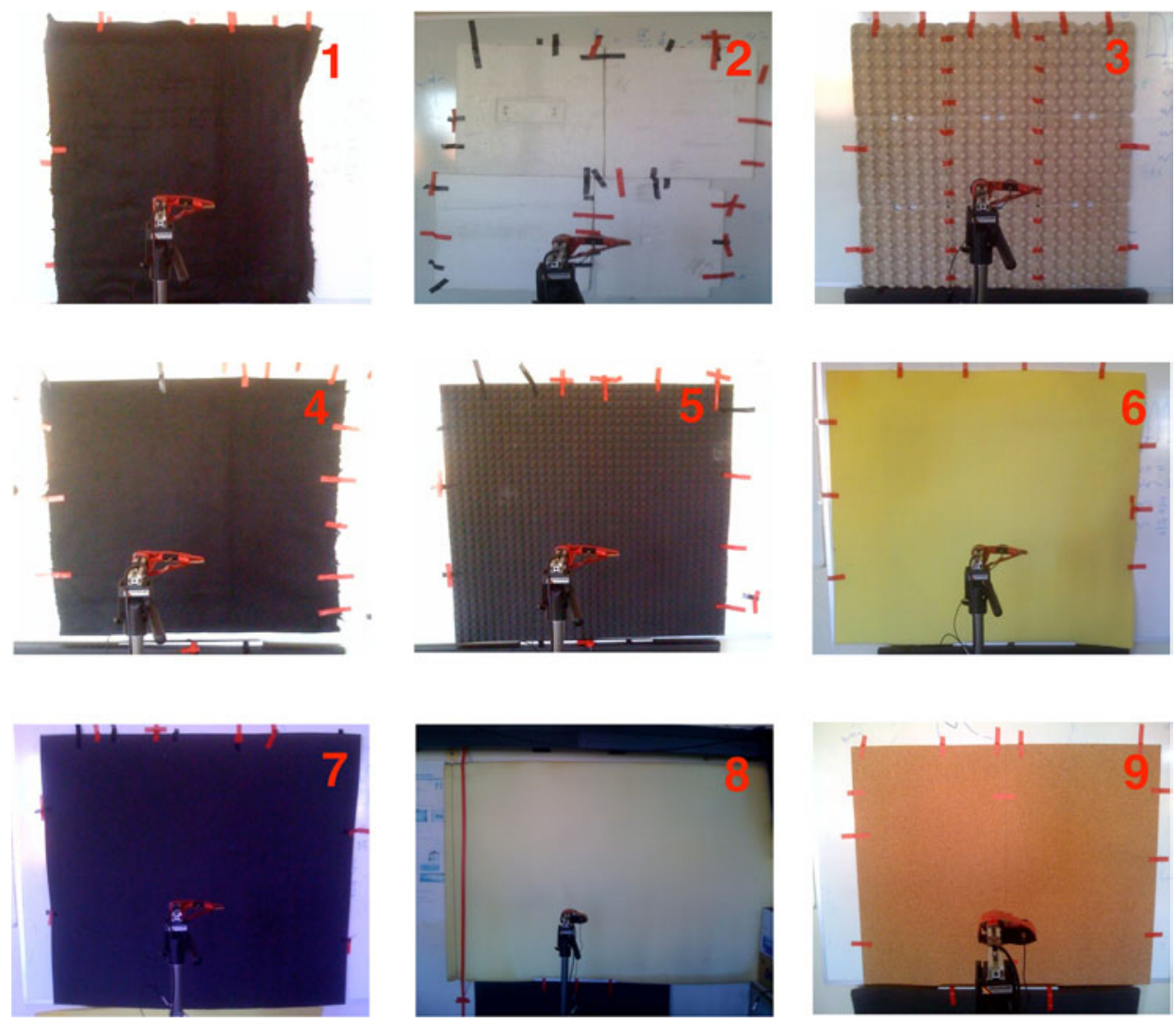

Figure 3. Materials used in the experiment 1, Felt fabric; 2 , expanded polystyrene; 3 , egg boxes; 4, coated egg boxes; 5 , foamtek - pyramidal foam; 6 , polyurethane foam $1 \mathrm{~cm} ; 7$, polyurethane foam $3 \mathrm{~cm} ; 8$, polyurethane foam $5 \mathrm{~cm}, 9$, agglomerated cork sheet $5 \mathrm{~mm}$.

materials, and this was especially noticeable at higher frequencies. Indeed, the 5-cm polyurethane foam was able to attenuate approximately $20 \mathrm{~dB}$ between 25 and $55 \mathrm{kHz}$, when compared with the board. In this range of frequencies, the average attenuation of the remaining materials was $15 \mathrm{~dB}$ ( $3 \mathrm{~cm}$ polyurethane), $8 \mathrm{~dB}$ (egg boxes coated with felt),

Table 1. Description of the materials used.

\begin{tabular}{lll}
\hline No. & Name & Description \\
\hline 1 & Felt fabric & Made of acrylic with $3 \mathrm{~mm}$ thickness \\
2 & Expanded polystyrene & Low-density type with $30 \mathrm{~mm}$ thickness \\
3 & Egg boxes & Made from recycled paper \\
4 & Coated egg boxes & $\begin{array}{l}\text { Felt fabric (M1) glued to the top of egg boxes (M3) } \\
\text { Polyurethane foam with pyramidal surface (AcustekPro, } \\
\text { http://www. acustekpro.com) }\end{array}$ \\
6 & Foamtek - pyramidal foam & Low firmness foam similar to Foamtek \\
6 & Polyurethane foam $1 \mathrm{~cm}$ & (M5). This low-cost foam is usually used in furniture \\
7 & Polyurethane foam $3 \mathrm{~cm}$ & Medium firmness foam \\
8 & Polyurethane foam $5 \mathrm{~cm}$ & Low firmness foam similar to M6 \\
9 & Agglomerated cork sheet $5 \mathrm{~mm}$ & Made from bonded cork granules \\
\hline
\end{tabular}



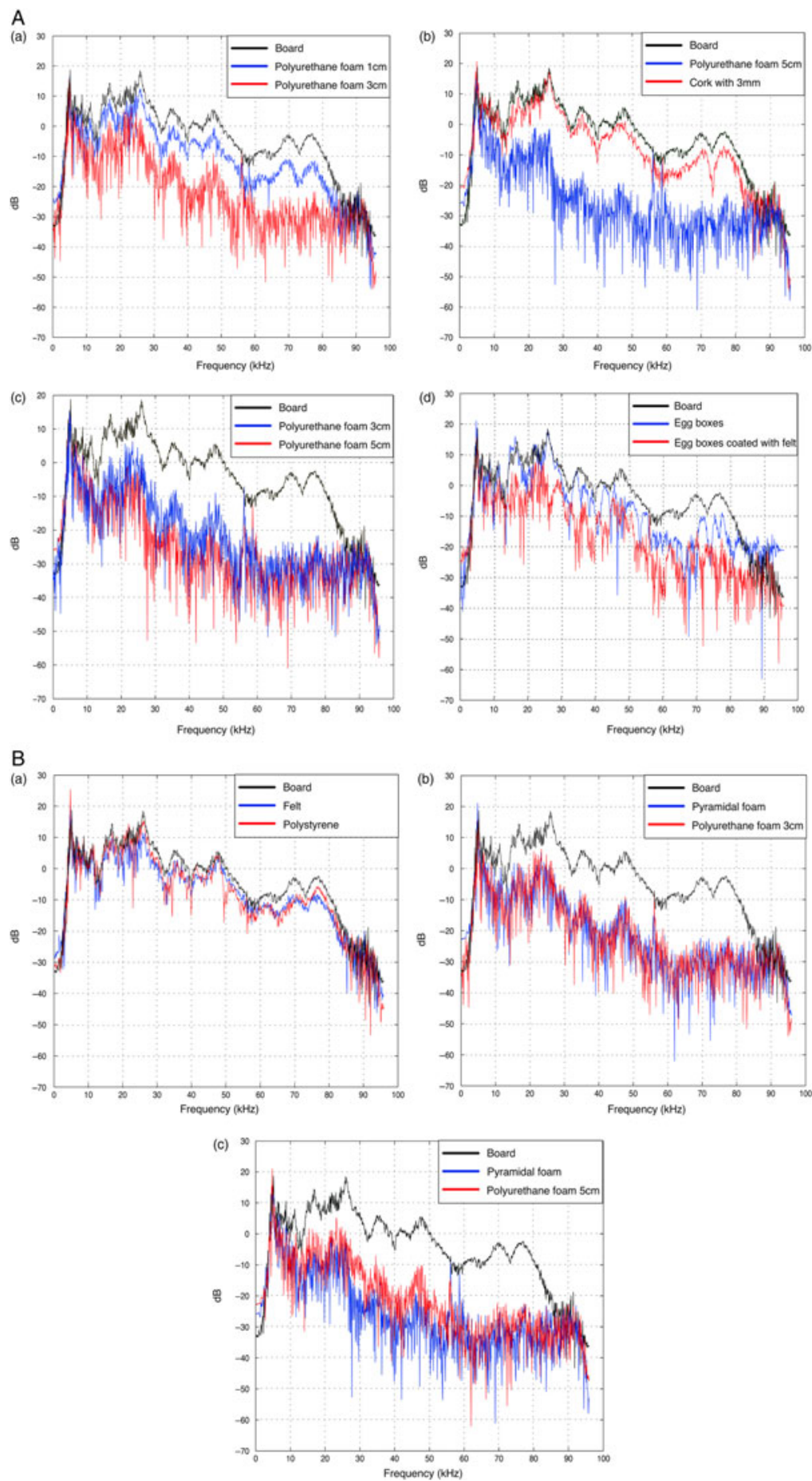

Figure 4. (A) Reflections in (a) polyurethane foam $1 \mathrm{~cm}$, polyurethane foam $3 \mathrm{~cm}$ and board; (b) polyurethane foam $5 \mathrm{~cm}$, cork and board; (c) polyurethane foam $3 \mathrm{~cm}$, polyurethane foam $5 \mathrm{~cm}$ and board; (d) egg boxes, egg boxes coated with felt and board. (B) Reflections in (a) felt fabric, polystyrene and board; (b) pyramidal foam, polyurethane foam $3 \mathrm{~cm}$ and board; (c) pyramidal foam, polyurethane foam $5 \mathrm{~cm}$ and board. 
$5 \mathrm{~dB}$ ( $1 \mathrm{~cm}$ polyurethane), $4 \mathrm{~dB}$ ( $3 \mathrm{~mm}$ cork), $4 \mathrm{~dB}$ (egg boxes), $3 \mathrm{~dB}$ (felt fabric) and $1 \mathrm{~dB}$ (polystyrene). So, for instance, when comparing the 5-cm polyurethane foam with the 3 $\mathrm{cm}$ polyurethane and absorbing pyramidal foams, it shows an additional attenuation of $5 \mathrm{~dB}$ between 25 and $55 \mathrm{kHz}$. On the other hand, felt fabric, polystyrene and the 3-mm cork presented the worst results in terms of ultrasound absorption (Figure 4).

\section{Discussion and conclusion}

To improve the results obtained with the felt fabric, it would probably be necessary to form the felt in the shape of waves, to decrease the energy of the reflected sounds (Everest and Pohlmann 2009). However, we decided not to test this scheme because bats could easily hide behind those waves. A thicker cork would perhaps present better absorption results (Carvalho et al. 1999), but it would significantly increase the costs (the 6-mm cork costs about twice the cost of the 3-mm cork).

We conclude that the polyurethane foam with $5 \mathrm{~cm}$ thickness presents the best quality-price relationship to acoustically coat a bat flight room because of the good results it presents at higher frequencies, and also because it is much cheaper than the material usually used for acoustic isolation. Other reasonable alternatives would be the $3-\mathrm{cm}$ polyurethane and absorbing pyramidal foams.

\section{Funding}

This research was supported by $R \& D$ project, Wind \& Biodiversity, co-financed by the European Regional Development Fund (FEDER), under the Regional Operational Programme of Center (Mais Centro). It was also supported by European Funds through COMPETE and by National Funds through the Portuguese Science Foundation (FCT) within projects PEst-C/MAR/LA0017/2013 and PEst-OE/EEI/UI0127/2014 [grant number CENTRO-07-0202-FEDER-011541].

\section{References}

Albuquerque D, Vieira J, Bastos C. 2009. Room acoustics simulator for ultrasonic robot location. Robótica 4(77):10-14.

Carvalho A, Vafiadis C, Borrego H. 1999. The use of agglomerated cork as underlay for improvement of impact sound insulation in buildings. In: 137th regular Meeting of the Acoustical Society of America and 2nd Convention of the European Acoustics Association: Forum Acusticum, Berlin, Germany.

Cox T, D'Antonio P. 2009. Acoustic absorbers and diffusers: theory, design and application. London: Taylor \& Francis. 495 p.

Everest FA, Pohlmann KC. 2009. Master handbook of acoustics. 5th ed. New York: McGraw-Hill.

Farina A. 2000. Simultaneous measurement of impulse response and distortion with a sweep-sine technique. In: AES 108th convention (preprint 5093), Paris, France. p. 19-22.

Griffin DR, Webster FA, Michael CR. 1958. The echolocation of flying insects by bats. Animal Behaviour VIII(3-4):141-154. 